\title{
Effect of Reactive Gas on the Wetting of Molten Iron-Carbon Alloy on Ceramic Substrates
}

\author{
Jari KURIKKALA, OIIi MATTILA, Timo FABRITIUS and Jouko HÄRKKI \\ Laboratory of Process Metallurgy, University of Oulu. P. O. Box 4300 Fl-90014 Finland.
}

(Received on June 26, 2009; accepted on December 14, 2000)

\begin{abstract}
Wetting phenomena have occupied an important position in the field of high temperature metal processing for a long time. The difficulties encountered in the high temperature experiments-especially the separation of one effect from another-have frustrated efforts to achieve a full understanding of the dynamic wetting phenomena which are present in many metallurgical applications.

In this work the sessile drop method is used to study the effect of reactive gases on the dynamic wetting angle of a binary iron-carbon mixture on a ceramic substrate. The use of such a mixture enables the effect of dynamic gas-liquid reactions to be separated from the solid-liquid interactions. An experiment performed with $\mathrm{SO}_{2}, \mathrm{O}_{2}$ and $\mathrm{N}_{2}$ gases at $1773 \mathrm{~K}$ proved that liquid surface tension can drop dramatically but the changes in wetting angle are only minor ones. It is also noted that the relative change in the volume of the droplet can give information about carbon boil and collapsing surface tension phenomena upon comparison with changes in the wetting angle of the droplet.
\end{abstract}

KEY WORDS: gas-liquid interface; iron-carbon melt; reactive wetting; sessile drop; wetting.

\section{Introduction}

Dynamic gas-liquid reactions play a major role in many metallurgical applications: 1) the dissolution of gases from gas to metal - and vice versa is well known in AOD, 2) the burning of carbon in refining metallurgy (BOF) producing gaseous $\mathrm{CO}_{2}$, and 3) $\mathrm{SiO}$ gas or sulphur-bearing gases react with iron droplets falling down in the dripping zone in a blast furnace hearth area. The reaction occurring at a gas-liquid interface affects the surface energy balance of the system, and thus the wetting conditions. It is well known that the mass transfer depends on the area between the reacting phases, which in turn are dependent on the wetting characteristics of the system, i.e. the size or shape of the droplets or bubbles.

Wetting phenomena has been studied widely in iron and steel manufacturing systems, covering various substrate materials and steel compositions, the majority of wetting measurements having been carried out in an inert atmosphere and being concentrated on solid-liquid interaction. Even the effect of crystal structures/orientation and surface roughness on the wetting angle has been studied by several authors. $^{1-4)}$ The effect of liquid-gas interaction, e.g. reactive gases, on the wetting of a liquid metal sample on a solid ceramic substrate has not been so well studied, however. Possible phenomena involved are: 1) the dissolution of gas molecules from gas to metal, ${ }^{5,6)} 2$ ) the reaction of one metal component on the metal surface, producing a gaseous product, $^{7,8)}$ and 3) a combination of these two, producing gaseous products and dissolving elements.

Kapilashrami et al. studied the effect of oxygen in a gas atmosphere on the wetting of pure iron on alumina, ${ }^{6)}$ silica ${ }^{9)}$ and mullite ${ }^{10)}$ surfaces, and observed that dissolved oxygen led to the formation of a product layer on the substrate, changing the wetting angle significantly. The effect of liquid-gas interaction on wetting behaviour could not be clearly separated from the liquid-solid interaction in these experiments. In the present work reactive gases were used to study the change in the wetting angle of a binary iron-carbon mixture on a ceramic substrate. The use of a binary iron-carbon mixture disables the formation of a product layer at the liquid-solid interface, allowing the effect of the dynamic gas-liquid reactions on wetting to be separated from the change in substrate surface.

\section{Experimental}

\subsection{Materials and Apparatus}

An iron-carbon alloy was made by melting down highpurity iron (99.98\%) and high-purity carbon $(99.9995 \%)$ in an oxygen-free atmosphere. A schematic diagram of the melting arrangements is shown in Fig. 1. Iron-carbon alloys were made with two carbon concentrations: $1 \mathrm{wt} \%$ and $2 \mathrm{wt} \%$.

The reactive $\mathrm{O}_{2}$ and $\mathrm{N}_{2}$ gases used in the experiments were supplied by AGA and $\mathrm{SO}_{2}$ by Messer. The compositions of the gases and impurities in them, as indicated by the manufacturer, are presented in Table 1. Since the aim of this research was to investigate liquid-gas interactions, the gases were chosen on the basis of their reactivity with molten iron and their relevance to metallurgical processes e.g. $\mathrm{BF}$ and $\mathrm{BOF}$. 


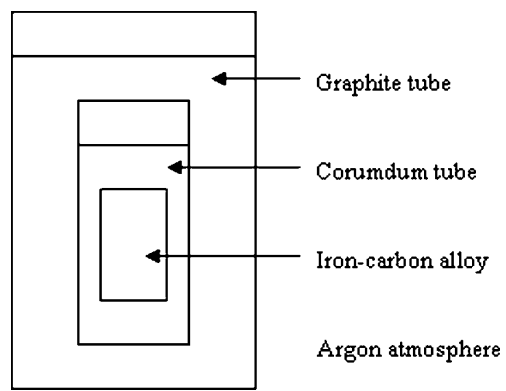

Fig. 1. Schematic diagram of the manufacturing of the iron-carbon alloy.

Table 1. Composition and impurities of the gases used in the sessile drop experiments.

\begin{tabular}{|c|c|c|}
\hline $\begin{array}{l}\text { Commercial } \\
\text { name }\end{array}$ & Composition & Impurities \\
\hline Ar 5.0 & $A_{r}>99,995 \%$ & $\begin{array}{c}\mathrm{H}_{2} \mathrm{O} \leq 2 \mathrm{ppm} \\
\mathrm{O}_{2} \leq 2 \mathrm{ppm}\end{array}$ \\
\hline $\mathrm{N}_{2} 5.0$ & $\mathrm{~N}_{2}>99,995 \%$ & \\
\hline Odorox & $\begin{array}{c}\mathrm{O}_{2}>99,5 \% \\
\mathrm{C}_{2} \mathrm{H}_{6} \mathrm{~S} 12 \mathrm{ppm}\end{array}$ & $\mathrm{H}_{2} \mathrm{O}<50 \mathrm{ppm}$ \\
\hline $\mathrm{SO}_{2}$ & $\mathrm{SO}_{2}>99,98 \%$ & $\begin{array}{c}\mathrm{H}_{2} \mathrm{SO}_{4} \leq 10 \mathrm{ppm} \\
\mathrm{H}_{2} \mathrm{O} \leq 50 \mathrm{ppm}\end{array}$ \\
\hline
\end{tabular}

Table 2. Chemical composition and impurity levels of the substrate materials.

\begin{tabular}{ccc}
\hline Material & $\begin{array}{c}\text { Chemical } \\
\text { composition }\end{array}$ & $\begin{array}{c}\text { Purity } \\
\text { level }\end{array}$ \\
\hline $\begin{array}{c}\text { Corundum } \\
\text { (polycrystalline) }\end{array}$ & $\mathrm{Al}_{2} \mathrm{O}_{3}$ & $99,7 \%$ \\
Periclase & $\mathrm{MgO}$ & $99 \%$ \\
Quartz & $\mathrm{SiO}_{2}$ & $\sim 99,9 \%$ \\
Sapphire & $\mathrm{Al}_{2} \mathrm{O}_{3}$ & $99,99 \%$ \\
(monocrystalline) & & \\
\hline
\end{tabular}

Corundum, periclase, quartz and sapphire were used as substrate materials in the experiments. The chemical compositions and purity levels of these substrates as indicated by the manufacturer are presented in Table 2.

A schematic diagram of the optical dilatometer used in the sessile drop experiments is shown in Fig. 2. The apparatus consisted of a horizontal corundum tube heated by silicon carbide resistor. The substrate and prepared iron sample were fed into the tube by means of a corundum shank connected to the other side of the furnace bracket. The gas was fed through the corundum shank in a stainless steel line. The temperature below the substrate was measured with an S-type thermocouple calibrated by melting highpurity copper and high-purity nickel. The flow of argon gas to the oven was controlled by a rotameter. $5 \mathrm{~mL}$ and $10 \mathrm{~mL}$ reactive gas pulses were inserted through a septum joint which consisted of a rubber gasket compressed to the end of the sideline of the gas pipe with a screw.

The oxygen content of the evacuating gas was measured with a Rapidox 2100 oxygen analyzer (Cambridge Sensotec) having a measurement range of $1 \cdot 10^{-20} \mathrm{ppm}-100 \%$.

A schematic diagram of the gas purification unit used to determine the effect of unpurified argon gas on the equilibrium contact angle is shown in Fig. 3. Its operation was

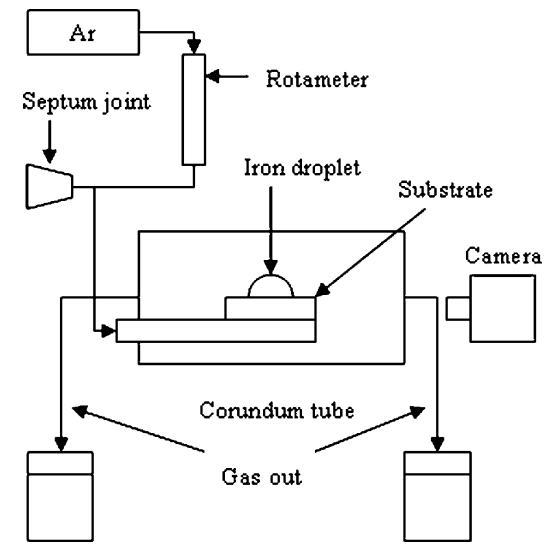

Fig. 2. Schematic diagram of the optical dilatometer used in the sessile drop experiments.

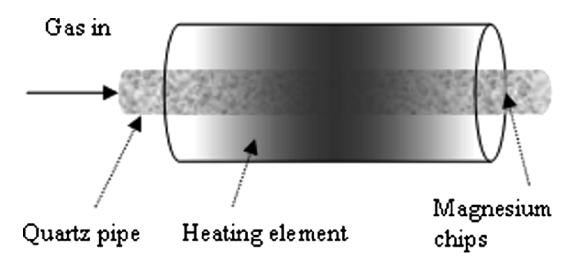

Fig. 3. Schematic diagram of the gas purification unit.

based on the feeding of gas through a quartz tube filled with magnesium chips heated to $823 \mathrm{~K}$. The purification unit enabled the oxygen content of the gas to be reduced from $1.5 \mathrm{ppm}$ to $\sim 1 \cdot 10^{-18} \mathrm{ppm}$.

The profile of the droplet was recorded by a camera through a quartz lens onto VHS tape, which was then digitalized using a video capturing apparatus. The video device was used to detect rapid changes in wetting. The wetting angle of the molten droplet as seen on frames captured from the video recordings of the experiment was measured using the image editing programs Gimp 2.4.6 and ImageJ $1.40 \mathrm{~g}$.

After the experiment the droplet and substrate were examined with Olympus SZX9 and Olympus BX51 microscopes. The experiments containing sulphur were also analysed with a Zeiss ULTRA plus Field Emission Scanning Electron Microscope.

\subsection{Procedure}

The experiments started with preparation of the metal samples, which were polished and heated to $383 \mathrm{~K}$ overnight to ensure a clean surface. The weight of the metal sample, for which the target was $0.4 \mathrm{~g}$, was measured with laboratory scales (Denver Instrument APX-200). The substrate materials were cut to a size of $15 \mathrm{~mm} \times 15 \mathrm{~mm} \times 4$ $\mathrm{mm}$. The sample and substrate were then carefully placed in the $\mathrm{Al}_{2} \mathrm{O}_{3}-\mathrm{MgO}$ element, which was situated on the end of the corundum shank. The substrate was balanced with the help of the camera, and finally the furnace was sealed up.

The gas flow to the oven was kept at $500 \mathrm{~mL} / \mathrm{min}$ for about $2 \mathrm{~h}$ before heating commenced, to ensure that the atmosphere in the oven had changed from air to argon. The oxygen content of the evacuated gas was measured and was seen to have stabilized $2 \mathrm{~h}$ after the start of inert gas feeding. The temperature of the dilatometer was raised to 
$1773 \mathrm{~K}$ at a rate of $10 \mathrm{~K} / \mathrm{min}$. Once the target temperature had been achieved the gas flow to the oven was reduced to $200 \mathrm{~mL} / \mathrm{min}$. Recording with the VHS recorder was started when the temperature had stabilized.

The gas pulse experiments were performed with a gas syringe through the septum joint, using volumes of $5 \mathrm{~mL}$ and $10 \mathrm{~mL}$ depending on the gas used. The furnace was left to cool down in an inert atmosphere after the experiment.

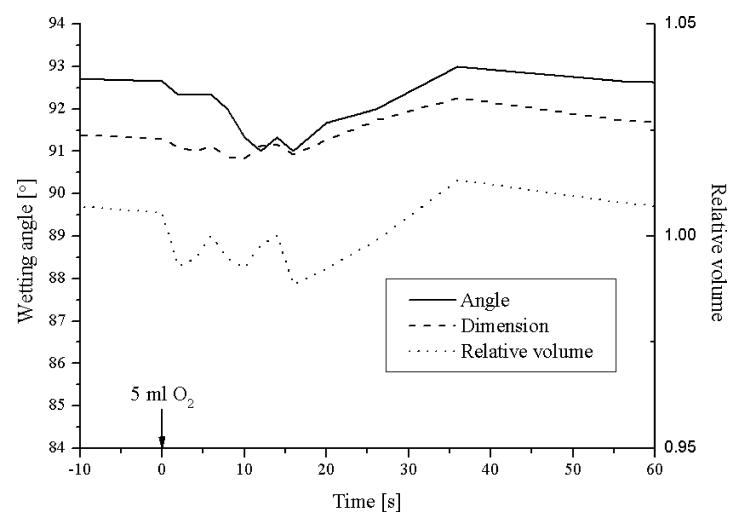

Fig. 4. Effect of a $5 \mathrm{~mL} \mathrm{O}_{2}$ pulse on the wetting angle and relative volume of a molten $\mathrm{Fe}-1 \% \mathrm{C}$ droplet on a corundum substrate.

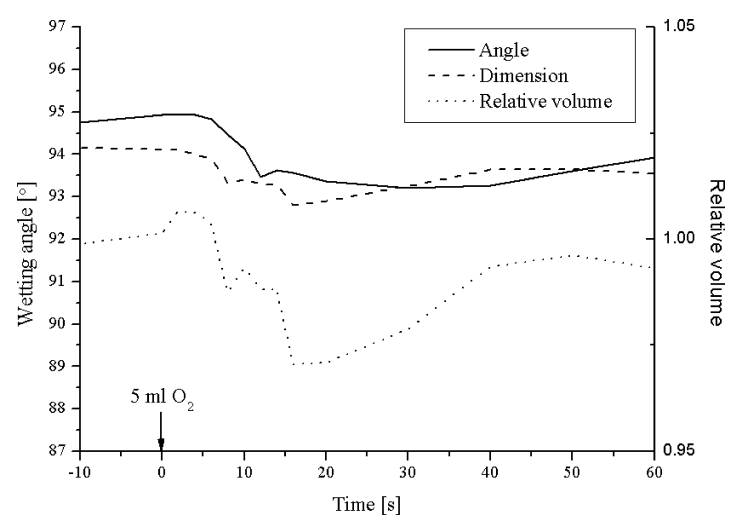

Fig. 5. Effect of a $5 \mathrm{~mL} \mathrm{O}_{2}$ pulse on the wetting angle and relative volume of a molten $\mathrm{Fe}-2 \% \mathrm{C}$ droplet on a corundum substrate.

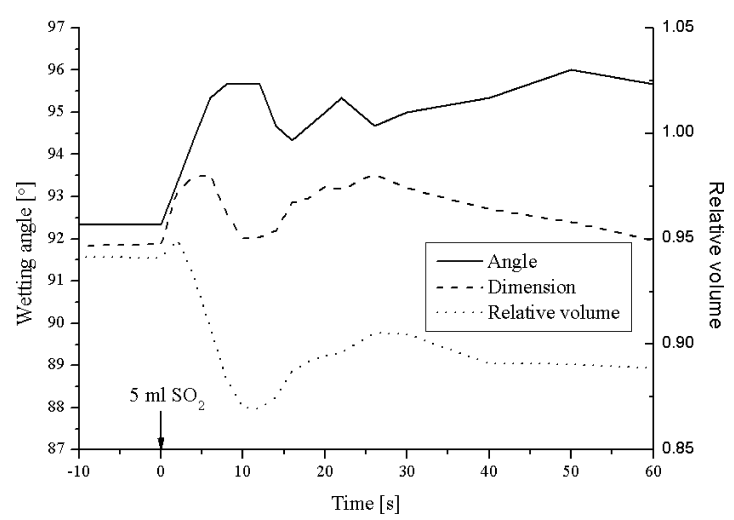

Fig. 6. Effect of a $5 \mathrm{~mL} \mathrm{SO} 2$ pulse on the wetting angle and relative volume of a molten $\mathrm{Fe}-1 \% \mathrm{C}$ droplet on a corundum substrate.

\section{Results}

The temperature in the sessile drop experiments was kept at $1773 \mathrm{~K}$. Experimental curves based on the measurements performed on the captured images are shown in Figs. 4-10. Two wetting angle measurement techniques were used: "angle" measurement based on determination of the wetting angle from the profile of the droplet by means of the image editing program, and "dimension" measurement was based on determination of the droplet height and the diame-

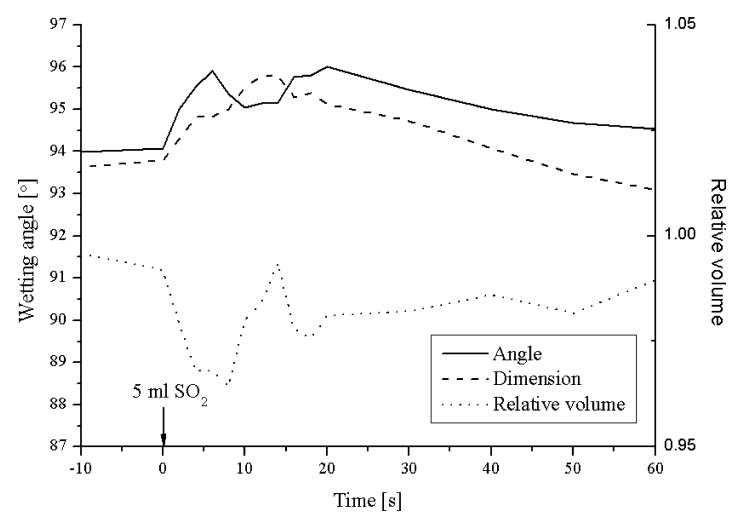

Fig. 7. Effect of a $5 \mathrm{~mL} \mathrm{SO}_{2}$ pulse on the wetting angle and relative volume of a molten $\mathrm{Fe}-2 \% \mathrm{C}$ droplet on a corundum substrate.

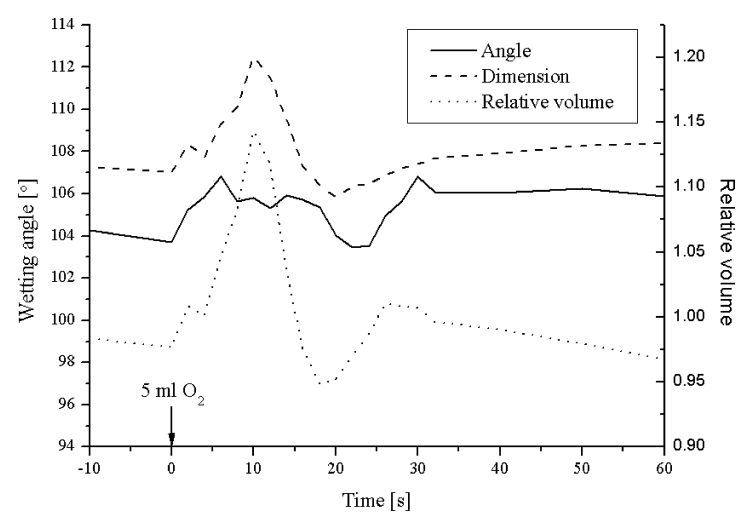

Fig. 8. Effect of a $5 \mathrm{~mL} \mathrm{O}_{2}$ pulse on the wetting angle and relative volume of a molten $\mathrm{Fe}-1 \% \mathrm{C}$ droplet on a periclase substrate.

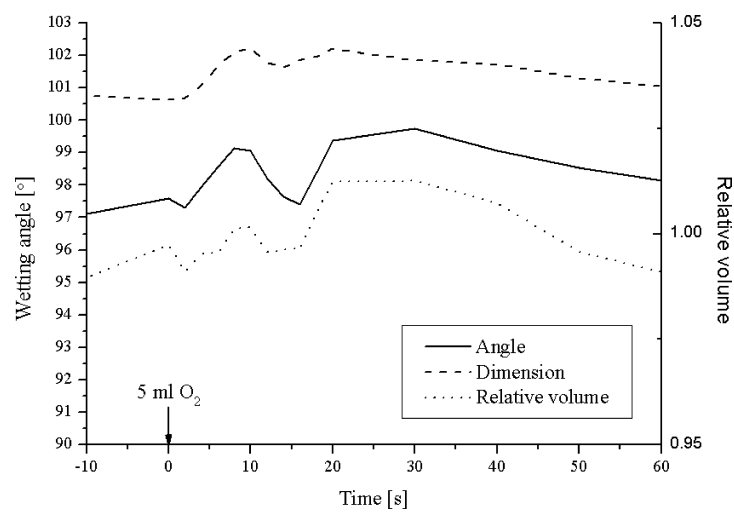

Fig. 9. Effect of a $5 \mathrm{~mL} \mathrm{O}_{2}$ pulse on the wetting angle and relative volume of a molten $\mathrm{Fe}-2 \% \mathrm{C}$ droplet on a periclase substrate. 


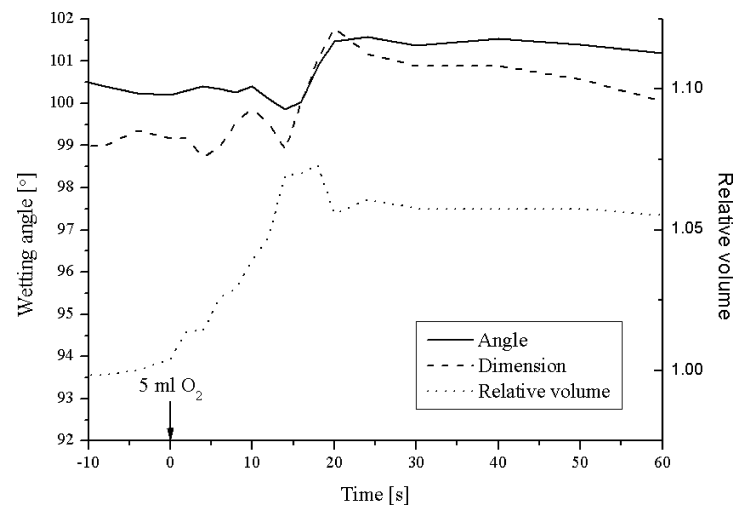

Fig. 10. Effect of a $5 \mathrm{~mL} \mathrm{O}_{2}$ pulse on the wetting angle and relative volume of a molten $\mathrm{Fe}-2 \% \mathrm{C}$ droplet on a sapphire substrate.

ter of the solid-liquid interfacial area followed by calculation of the wetting angle using the equations for an ideal spherical cap. Figs. 4-10 also include curves showing the changes in relative droplet volume as calculated on the basis of this "dimension" measurement.

The effect of a $5 \mathrm{~mL}$ oxygen gas pulse on the wetting of the molten $\mathrm{Fe}-1 \mathrm{wt} \%$ carbon droplet is plotted in Fig. 4. The equilibrium contact angle before gas feeding was about $92^{\circ}$, which was lower than that observed in a pure iron melt on a corundum surface. ${ }^{6}$ ) Differences in wetting angle are assumed to originate from different alumina substrate characteristic, crystal orientation and surface roughness, or differences in melt chemistry. The changes observed in the wetting angle were minor, although noticeable gas formation was seen around the molten droplet. The oxygen pulse experiment performed with an $\mathrm{Fe}-2 \%$ carbon melt was exhibited behaviour similar to that seen in Fig. 5 .

In the sulphur dioxide experiments (Figs. 6 and 7) the wetting angle in both materials increased after feeding of the gas pulse. The sulphur dioxide gas caused movements of the droplet on the solid surface, which were assumed to be caused by the dissolving of highly surface-active sulphur through the liquid-gas interface, generating surface tension gradients and flows, Marangoni convection, on the surface of the molten droplet. The decrease in the relative volume curve for an $\mathrm{Fe}-1 \% \mathrm{C}$ melt after a sulphur dioxide pulse can be seen in Fig. 6.

Periclase and sapphire substrates were used to produce different equilibrium wetting angles from the experiments performed on the corundum substrate, and the effects of an oxygen pulse on $\mathrm{Fe}-1 \% \mathrm{C}$ and $\mathrm{Fe}-2 \% \mathrm{C}$ droplets are shown in Figs. 8 and 9. Experimental curves based on the oxygen pulse experiment with an $\mathrm{Fe}-2 \% \mathrm{C}$ melt on a sapphire substrate are shown in Fig. 10.

The effect of nitrogen on the wetting of a molten ironcarbon alloy was also investigated, but the differences in the contact angles were too small (about $1^{\circ}$ ) relative to the measurement accuracy. Only small changes had been expected, however, due to poor dissolving of nitrogen in the iron-carbon melt. ${ }^{5)}$

Experiments with a quartz substrate showed that the iron-carbon melt reacted with the solid substrate. Silicon dioxide was reduced by the carbon in the iron, producing silicon, which dissolved in the iron. The resulting carbon

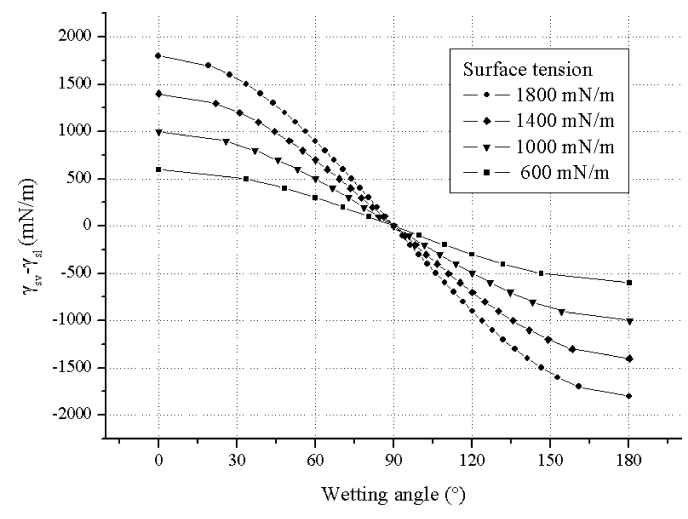

Fig. 11. Effect of surface tension and the gas-solid and liquidsolid interfacial tension difference on wetting behaviour, based on Young's equation.

monoxide gas was evacuated from the solid-liquid interface. This was seen to cause movements of the iron-carbon droplet that affected determination of the wetting angle.

\section{Discussion}

Young's equation ${ }^{11)}$ (Eq. (1)), as examined in Fig. 11, shows that collapsing surface tension near the equilibrium wetting angle of $90^{\circ}$ causes only minor changes in wetting angle. When the equilibrium wetting angle is higher than $90^{\circ}$ a decrease in surface tension should be seen as an increased wetting angle, and conversely, when the wetting angle is lower than $90^{\circ}$ a decrease of the surface tension should be seen as a decreased wetting angle.

$$
\gamma_{\mathrm{sv}}-\gamma_{\mathrm{sl}}=\gamma_{\mathrm{lv}} \cos \theta
$$

According to Fig. 11 the changes in the tension of the solid-liquid interface can also be characterized. There have been several investigations in which a new product layer has been observed at this interface, ${ }^{6,9-10)}$ in which case the interfacial tension between the product layer and the molten droplet is lower than it was in initial state and should be reflected in a decrease in the contact angle. The extent of the change in the wetting angle, however, will be highly influenced by the surface tension of the melt. Although this exploration of Young's equation is valid only in the ideal case, it is consistent with the experiments presented in Figs. $4-10$.

\subsection{Oxygen Pulse Experiments}

The oxygen pressure measurements are not comparable between experiments due to differences in the gas flow through the oxygen measurement unit. The gas flow rate had a significant effect on the measured value of the oxygen content at a low flow rate. The gas flow out of the oven was controlled by leading the gas lines under the water bath and using the water pillars to ensure that gas was flowing out of both ends of the corundum tube. This behaviour was prioritized at the expense of accurate oxygen partial pressure measurements between the experiments.

The effect of oxygen as an impurity in argon gas on the wetting phenomena was investigated using the oxygen purification unit. The measured difference between the equilibrium contact angles of an iron-carbon melt on a corun- 
dum substrate using either purified or unpurified gas was a couple of degrees. The effect of the trace oxygen is within the range of measurement accuracy.

It was assumed in the oxygen pulse experiments that oxygen would dissociate and dissolve in the surface of the melt according to Eq. (2) and react with the carbon to form carbon monoxide according to Eq. (3), the latter being seen as a gas cloud around the droplet.

$$
\begin{gathered}
\frac{1}{2} \mathrm{O}_{2}(\mathrm{~g})=[\mathrm{O}]_{\mathrm{Fe}} \ldots . \\
{[\mathrm{C}]_{\mathrm{Fe}}+[\mathrm{O}]_{\mathrm{Fe}}=\mathrm{CO}(\mathrm{g}) . .}
\end{gathered}
$$

It was evident from oxygen pulse experiments on a corundum substrate (Figs. 4 and 5) that the decrease in the contact angle, which according to Fig. 11 should be reflected in an increased contact angle, was only a minor one. Carbon boil phenomena were also observed in the oxygen pulse experiment with the $\mathrm{Fe}-1 \% \mathrm{C}$ melt, but not with the $\mathrm{Fe}-2 \% \mathrm{C}$ melt. Oxygen molecules colliding with the surface of the melt have a higher probability of dissolving in the melt when the carbon concentration is lower. As a consequence of the fact that carbon monoxide gas was formed inside the droplet, the melt burst out of the droplet once the gas bubble had penetrated to the gas-liquid interface. This phenomenon has been investigated in several publications. ${ }^{7,12}$ )

\subsection{Sulphur Dioxide Pulse Experiments}

The contact angle changes caused by the gas pulse were larger in the sulphur dioxide experiments than in the oxygen pulse experiments. It was believed that sulphur dioxide would dissociate on the surface of the melt (Eq. (4)) and that the oxygen would react with the carbon according to Eq. (3).

$$
\mathrm{SO}_{2}(\mathrm{~g})=[\mathrm{S}]_{\mathrm{Fe}}+2[\mathrm{O}]_{\mathrm{Fe}}
$$

The larger effect of $\mathrm{SO}_{2}$ pulses on the contact angle than of $\mathrm{O}_{2}$ pulses was considered to be caused by the highly surface-active nature of the sulphur in the $\mathrm{Fe}-\mathrm{C}$ melt. According to thermodynamic calculations, the equilibrium oxygen content that is buffered by the carbon inside the droplet is about $19 \mathrm{ppm}$ for the $\mathrm{Fe}-1 \% \mathrm{C}$ melt and about $9 \mathrm{ppm}$ for the $\mathrm{Fe}-2 \% \mathrm{C}$ melt. Thus the differences in contact angle could be explained by the larger amount of sulphur on the surface of the melt in the sulphur dioxide experiment compared with the amount of dissolved oxygen in the oxygen pulse experiments. According to Divakar et al., even small amounts of sulphur can reduce the surface tension of the iron-carbon alloy significantly. ${ }^{13)}$

It was seen in Fig. 6 that the relative volume of the droplet was reduced just after the sulphur dioxide pulse was fed in. This is the sign of collapsed surface tension. The geometry of the droplets changed from an ideal spherical cap to a more flattened profile, so that the surface forces were overshadowed by the gravity forces. It can also be seen in Fig. 6 that the two wetting angle measurement methods provided similar results before feeding of the gas pulse, but the gap between them increased after the pulse, which could mean that the surface tension of the melt had changed dramatically. The carbon boil phenomenon was also noted in the sulphur dioxide experiments with both the

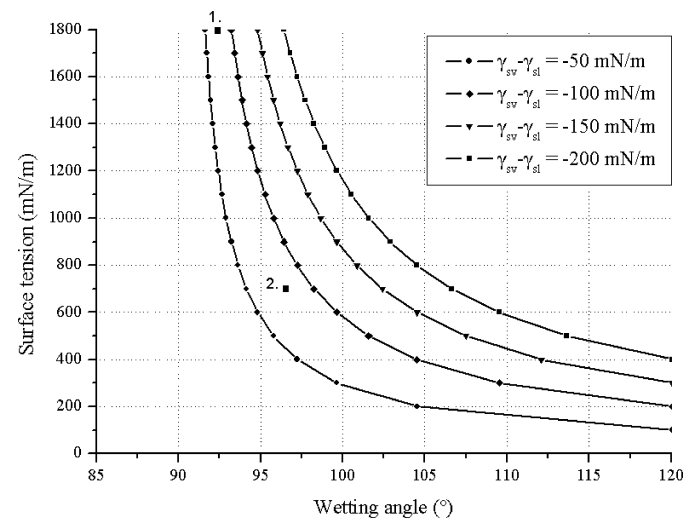

Fig. 12. Effect of surface tension on wetting behaviour, based on Young's equation, with four gas-solid and liquid-solid interfacial tension differences. Two dots indicate the surface tension changes in the sulphur dioxide experiment with a $\mathrm{Fe}-1 \% \mathrm{C}$ melt (1. before the pulse and 2 . after the pulse).

$\mathrm{Fe}-1 \% \mathrm{C}$ and $\mathrm{Fe}-2 \% \mathrm{C}$ melts about $10 \mathrm{~s}$ after the pulse was fed in. Although this cannot be seen in the wetting angle measurements, it is believed that when the surface tension is smaller the gas bubbles burst through the liquid-gas interface more easily and only minor changes are seen in the measured wetting angle and the volume of the droplet. It has been demonstrated that a decrease in surface tension can enhance the bursting of a melt. ${ }^{7)}$

Young's equation can be used to determine the magnitude of the surface tension reduction in the experiments. The effect of reducing the surface tension on the wetting behaviour is shown in Fig. 12. In the sulphur dioxide experiment with the $\mathrm{Fe}-1 \% \mathrm{C}$ melt the wetting angle increased by about 4 degrees (Fig. 6), a change that would require the surface tension to decrease from 1800 to $700 \mathrm{mN} / \mathrm{m}$ according to Fig. 12. Thus the changes in wetting angle near the equilibrium wetting angle of $90^{\circ}$ are small, but the surface tension changes dramatically.

\subsection{Experiments with Different Substrates}

The effect of different substrates on the equilibrium wetting angle was investigated in order to obtain larger wetting angle changes in response to reactions on the gas-liquid interface. In the oxygen pulse experiments the equilibrium wetting angle on a periclase substrate (Figs. 8 and 9) was higher than that on a corundum substrate (Figs. 4 and 5), and it increased further after the gas pulse. This is in agreement with Fig. 11. Meanwhile, the relative volume curve in Fig. 8 increased about $15 \%$ after the gas pulse, which indicates that gas is formed inside the $\mathrm{Fe}-1 \% \mathrm{C}$ droplet. The carbon boil phenomenon was not observed in the experiment with a $\mathrm{Fe}-2 \% \mathrm{C}$ droplet on a periclase substrate.

The sapphire surface was smoother than the corundum or periclase substrates, and the droplet moved back and forth even before the pulse was fed in. This may have been due to trace oxygen in the gas, inducing Marangoni convection. The differences in solid-liquid energy states between locations can be smaller on a smooth surface than on a rough surface, so that less force is required to move the droplet. The relative volume curve in Fig. 10 rises slowly for $15 \mathrm{~s}$, 


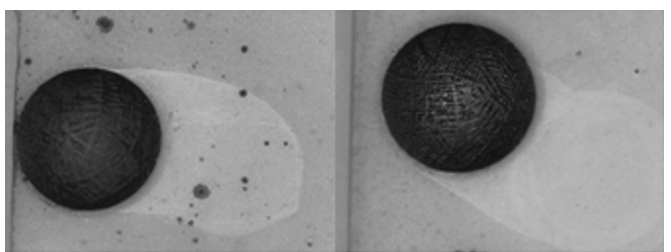

a)

b)

Fig. 13. a) $\mathrm{An} \mathrm{Fe}-1 \% \mathrm{C}$ droplet and b) an $\mathrm{Fe}-2 \% \mathrm{C}$ droplet on a corundum substrate after the oxygen pulse experiments.

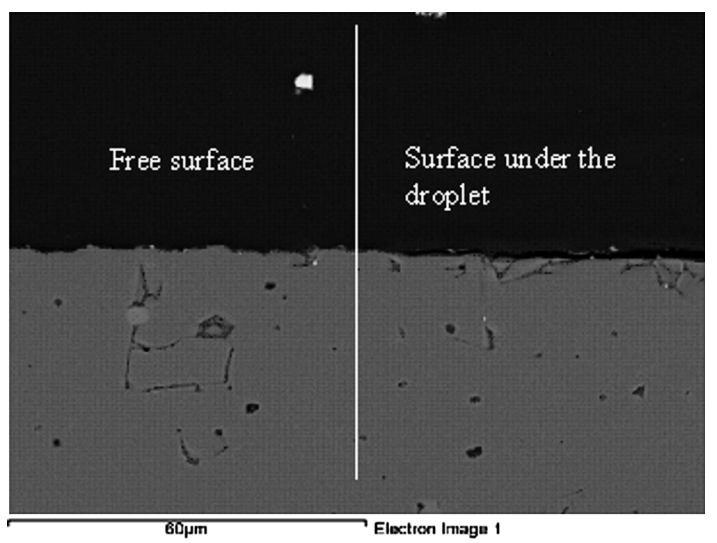

Fig. 14. FESEM image of the corundum substrate surface after the $\mathrm{SO}_{2}$ pulse experiment with an $\mathrm{Fe}-1 \% \mathrm{C}$ droplet.

possibly on account of droplet movement on the surface. After the increase in relative volume the wetting angle also rises about $2^{\circ}$.

\subsection{Changes at the Solid-Liquid Interface}

The images in Fig. 13 showing the droplets and substrates after the oxygen pulse experiments reveal a burst melt in the $\mathrm{Fe}-1 \% \mathrm{C}$ droplet experiment, and also suggest that the sample moved on the surface of the substrate, which can be partly explained by inadequate horizontal placement of the substrate. Although the levelling was carried out carefully using the camera, the method is not an entirely accurate one.

It can also be seen in Fig. 13 that the area below the droplet has changed, as was also the case in the experiments using purified argon gas $\left(p_{\mathrm{O}_{2}} \sim 1 \cdot 10^{-18} \mathrm{ppm}\right)$. It is thus thought that the rough surface was smoothed by the moving droplet, as it can be seen from Fig. 14 that the trace oxygen in the argon gas did not have any substantial influence on the experiments.

Characterization of the solid-liquid interface in the sulphur dioxide experiments using the Field Emission Scanning Electron Microscope pointed to layers containing $\mathrm{FeO}$ and FeS, as seen in Fig. 15, which were the cause of the decrease in contact angle shown in Fig. 16 after 1 min of feeding in the additional $10 \mathrm{~mL} \mathrm{SO}_{2}$ pulse.

\subsection{Accuracy of the Measurements}

Variations in the equilibrium wetting angle between experiments are affected by the position of the substrate relative to the camera, the homogeneity of the melt, the amount of melt, air leaks into the atmosphere in the oven, droplet movements on the surface and the hysteresis phenomenon.

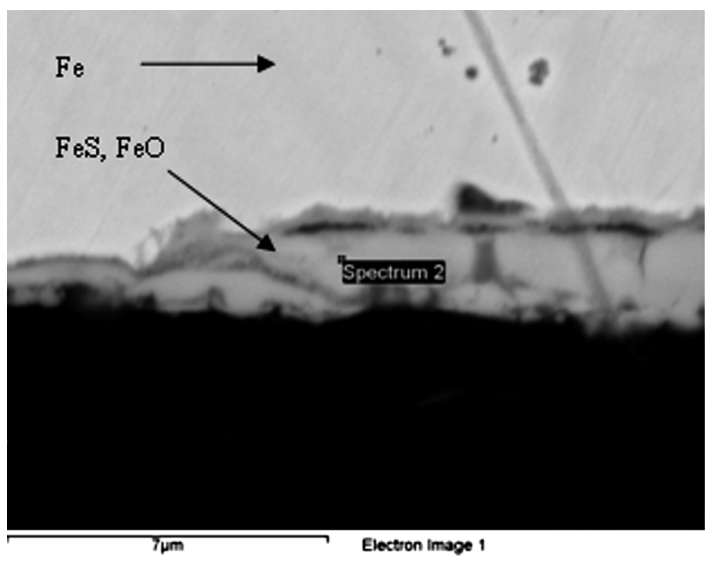

Fig. 15. FESEM image of the interface between the $\mathrm{Fe}-2 \% \mathrm{C}$ droplet and the corundum substrate after the sulphur dioxide pulses.

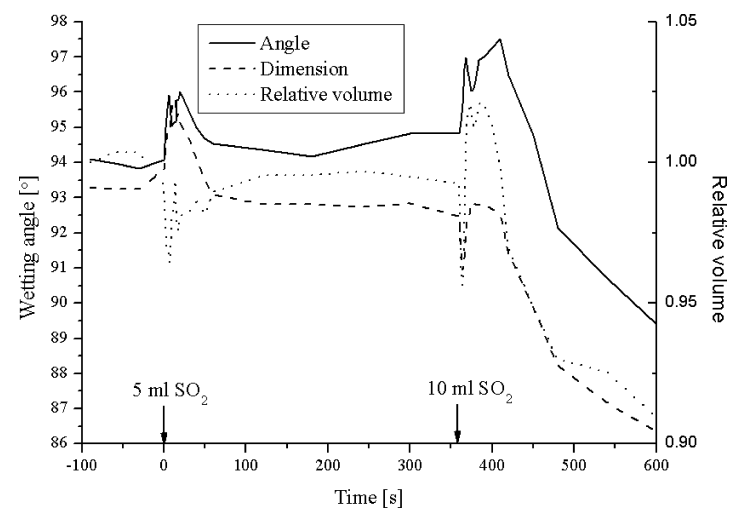

Fig. 16. Effect of $5 \mathrm{~mL}$ and $10 \mathrm{~mL} \mathrm{SO}$ pulses on the wetting angle and relative volume of a molten $\mathrm{Fe}-2 \% \mathrm{C}$ droplet on a corundum substrate.

According to the measured values of the angles, the scatter in the equilibrium wetting angles is within a range of \pm 5 degrees.

It is believed, however, that the measured values within one experiment are more accurate. The "dimension" measurement technique is accurate if the shape of the droplet is an ideal spherical cap, and it is considered that the accuracy of the wetting angle measurement itself is within \pm 1 degrees, although it was noticed that there was a difference between "dmension" and "angle" measurement techniques within the same experiment. The "dimension" measurement accuracy is affected by the deviation of the droplet shape from the ideal, but when tested, the droplet proved small enough that its shape remained close to the ideal spherical cap. The shape of the droplet can change after the pulse has been fed in, however, as can be seen from the relative volume curve in Fig. 6. This detracts from the accuracy of the "dimension" measurement technique.

Thus the overall accuracy of the equilibrium wetting angle measurement is believed to be the largest margin between the angles given by the two measurement techniques, which is found in the oxygen pulse experiment with the $\mathrm{Fe}-2 \% \mathrm{C}$ melt on a periclase substrate (Fig. 9), about $3^{\circ}$.

It was also noted that there is a difference between the wetting angle changes measured with the two techniques. The dynamic wetting angle measured with the "dimension" 
technique is affected by the shape of the droplet, and if the surface tension has been exceeded by the gravity forces, flatten the droplet more, the "dimension" technique gives a lower value for the wetting angle, as seen in Figs. 6 and 7, whereas if the droplet becomes more swollen the "dimension" technique gives a higher value for wetting angle, as seen in Fig. 8.

The change in wetting angle measured by the "angle" measurement technique can also be influenced by the shape of the droplet, depending on how close to the three-phase solid-liquid-gas point the wetting angle can be measured. If the droplet is flattened in shape, the "angle" technique will give a higher value for the wetting angle, if it becomes more swollen, the "angle" measurement gives a lower value. The point on the liquid-gas interface through which the line for measuring the wetting angle is drawn alters depending on the shape of the droplet. So measuring the wetting angle with the "dimension" and "angle" techniques gives a lower and an upper limit for the dynamic wetting angle.

\section{Summary and Conclusions}

The aim of this research was to illustrate dynamic wetting changes due to reactions at the gas-liquid interface. Using an iron-carbon alloy, a product layer was formed on the solid-liquid interface in response to consecutive injections in the experiments containing sulphur, but the effect of the gas-liquid reactions on the wetting behavior could be separated from the solid-liquid phenomena.

Reactions at the liquid-gas interface can affect the contact angle of the molten iron-carbon alloy on a ceramic substrate. It was seen here that the changes in the wetting angle of an iron-carbon melt on a corundum or periclase substrate were small when using oxygen or sulphur dioxide as the reactive gas. This is in agreement with Young's equation in its ideal form, whereby the declining surface tension near the equilibrium wetting angle of $90^{\circ}$ causes only minor changes in the wetting angle. The cause of the decline in surface tension was traced to the decrease in the relative volume of the droplet.

It was difficult to illustrate the effect of any one manipulation on the wetting, as the wetting angle measurements can be influenced by the carbon boil phenomenon, although the cause of the latter was traced to the increase in the relative volume of the droplet.

\section{Acknowledgements}

The authors would like to thank Mr. Riku Mattila and Mr. Tommi Kokkonen for the technical support and fruitful ideas on the topic of the research. Financial support from the Academy of Finland is gratefully acknowledged.

\section{REFERENCES}

1) P. Shen, H. Fujii, T. Matsumoto and K. Nogi: Acta Mater, 51 (2002), 4897.

2) R. N. Wenzel: Ind. Eng. Chem., 28 (1936), 988.

3) Y.-J. Sheng, S. Jiang and H.-K. Tsao: J. Chem. Phys., 127 (2007), 234704.

4) A. B. D. Cassie and S. Baxter: Trans. Fadaray Soc., 40 (1944), 546.

5) D. W. Gomersall, A. McLean and R. G. Ward: Trans. Metall. Soc. AIME, 242 (1968), 1309.

6) E. Kapilashrami, A. Jakobsson, A. K. Lahiri and S. Seetharaman: Metall. Mater. Trans. B, 34 (2003), 193.

7) H. Sun, K. Gao, V. Sahajwalla, K. Mori and R. D. Pehlke: ISIJ Int., 39 (1999), 1125

8) E. T. Turkdogan: Fundamentals of Steelmaking, The Institute of Materials, Cambridge, (1996), 38, 95.

9) E. Kapilashrami, A. K. Lahiri, A. W. Cramb and S. Seetharaman: Metall. Mater. Trans. B, 34 (2003), 647.

10) E. Kapilashrami, V. Sahajwalla and S. Seetharaman: ISIJ Int., 44 (2004), 653.

11) T. Young: Philos. Trans. R. Soc. (London), 95 (1805), 65.

12) K. Gao, V. Sahajwalla, H. Sun, C. Wheatley and R. Dry: ISIJ Int., 40 (2000), 301.

13) M. Divakar, J. P. Hajra, A. Jakobsson and S. Seetharaman: Metall. Mater. Trans. B, 31 (2000), 267. 